\title{
Polícia Federal: Função Vertebradora, combate à CorrupÇão e os Desvios de Conduta Policial
}

\author{
Carlos frederico Portella Santos Ribeiro \\ UNIVERSIDADE DE BRASÍLIA \\ Polícia Federal - DF
}

Joselito de Araujo Sousa

UNIVERSIDADE DE BRASÍlIA

Polícia Federal - DF

Nelson Levy KNeip de Freitas Macedo

UNIVERSIDADE DE BRASÍlIA

Polícia Federal - DF

\section{Siegrid Guillaumon Dechandt}

UNIVERSIDADE DE BRASÍLIA

\section{RESUMO}

O artigo aborda, de forma teórica, a função vertebradora da Polícia Federal (PF) no enfrentamento à corrupção, iniciando pelo enfrentamento a casos envolvendo seus próprios servidores. Foi feito levantamento junto à Controladoria-Geral da União (CGU) de dados de punições de servidores públicos federais por corrupção e outras causas. Foi feita também análise de notícias publicadas em jornais de grande circulação a respeito de prisões de policiais federais por corrupção, como fenômeno decorrente do combate à corrupção interna. Os resultados comparativos mostram rigidez muito maior com que a Polícia Federal trata os casos de corrupção interna em relação aos demais órgãos do Poder Executivo Federal, tendo sido expulsos, no período compreendido entre 2003 a 2019, oito vezes mais servidores do Poder Executivo federal, por envolvimento em casos de corrupção, em relação à média geral.

Palavras-Chave: Corrupção. Função vertebradora. Polícia federal brasileira. Servidor público. 


\section{INTRODUÇÃo}

A corrupção é um mal que atormenta todas as sociedades do mundo e os incidentes de corrupção têm sido um enigma duradouro na sociedade humana (HUANG; CHEN; WANG, 2018). A corrupção afeta o Estado de variadas formas, a exemplo do investimento estrangeiro direto - IDE, que é afetado negativamente tanto pelo nível de corrupção no país de acolhimento como pelas diferenças nos níveis de corrupção do país anfitrião (BRADA; DRABEK; MENDEZ; PEREZ, 2019). Repercute diretamente no crescimento econômico ao promover a incerteza e ao dificultar o investimento (CIEŚLIK; GOCZEK, 2018), também afetando, sobremodo, as atitudes em relação à credibilidade do governo em virtude da percepção pública da corrupção (HONGXIA ZHANG, 2019).

Do mesmo modo, segundo Cooray e Dzhumashev (2018), a corrupção afeta a oferta de mão-de-obra no setor formal, reduzindo a produtividade, alterando a oferta de trabalho na economia paralela, alterando a carga tributária e distorcendo o equilíbrio entre poupança e consumo, entre outros efeitos deletérios percebidos e outros ainda por serem desvelados. Enfim, a corrupção causa consequências que podem impulsionar ou atrasar a modernização (FILGUEIRAS, 2009), considerando-se, ainda, que conjunturas de ampla corrupção expressam uma pequena institucionalização política (HUNTINGTON, 1975).

Para Furtado (2015), é difícil definir corrupção, sendo mais fácil relacioná-la a situações que exprimem abuso de poder, desvio de finalidade pública e uso de potestades públicas para fins privados. Esse vácuo conceitual pode ainda ser percebido em instrumentos convencionais importantes, a exemplo, em âmbito regional, da Convenção Interamericana contra Corrupção, que foi promulgada entre nós pelo Decreto n. ${ }^{\circ} 4.410 / 2002^{1}$. Essa convenção, apesar de não definir o que é corrupção, ocupou-se em delimitar seu âmbito de aplicação a determinados atos de corrupção (artigo VI). Já a Convenção da Nações Unidas contra a Corrupção, também conhecida como Convenção de Mérida, que foi subscrita pelo Brasil e incorporada ao nosso ordenamento pelo

1 Disponível em: http://www.planalto.gov.br/ccivil_03/decreto/2002/D4410a.htm. Acesso em: 16 nov. 2020 
Decreto n. ${ }^{\circ} 5.687 / 2006^{2}$, não se ocupou de definir, formalmente, o que é corrupção.

Apesar da ausência de uma definição conceitual normativa corrente, para os fins deste artigo, cedendo a um apelo delimitativo e sem embargos de outros sentidos possíveis, a ideia de corrupção estará relacionada com os sentidos de transgressão ou violação de uma regra e de obtenção de vantagem ilegítima. Com base nisso, corrupção será compreendida como uma conduta (comissiva ou omissiva) praticada por um integrante de uma organização ou instituição, em razão de sua importância na hierarquia da mesma, podendo emitir decisões e ter privilégio no acesso às informações, visando a conseguir vantagem para si ou terceiros, havendo uma permuta de vantagem econômica ou pessoal (ANDVIG, 2004).

Por outro lado, no campo organizacional público, o estudo da corrupção encontra eco e relevância nos atos de controle da Administração Pública, os quais, no dizer de Carvalho Filho (2019), conformam um aporte de mecanismos jurídicos e administrativos por meio dos quais se exerce o poder de fiscalização e de revisão da atividade administrativa em qualquer das esferas de poder.

Sob uma perspectiva subjetiva, que realce atores envolvidos, pode-se afirmar que atuam no combate à corrupção hoje no Brasil a Controladoria Geral da União (CGU), a Advocacia Geral da União (AGU), o Tribunal de Contas da União (TCU), o Ministério Público Federal (MPF), a Justiça Federal (JF) e a Polícia Federal (PF), sendo esta última objeto de estudo neste artigo.

Conforme salientado por Olivieri (2011), estudos contemporâneos indicam que as instituições de combate à corrupção possuem razoável estrutura para cumprir seus objetivos institucionais. Entretanto, não possuem um adequado compartilhamento de ações dentro do ciclo de combate à corrupção, de forma a tornar tal combate mais efetivo. Ou seja, a sobreposição de ações idênticas, realizadas por instituições distintas, poderá gerar retrabalho, perda de tempo e ineficiência das mesmas, acabando por não se chegar à punição efetiva dos atos

2 Disponível em: http://www.planalto.gov.br/ccivil_03/_Ato2004-2006/2006/Decreto/D5687. htm. Acesso em: 16 nov. 2020. 
de corrupção praticados. A mesma autora continua expondo que:

As instituições brasileiras que atuam no ciclo do combate à corrupção apresentam um paradoxo: elas são fortes, ativas e relativamente bem estruturadas (muitas são independentes e seus funcionários são bem formados e remunerados), mas o resultado final é fraco, pois muitos casos só são descobertos depois de grandes prejuizos ao erário, a punição demora ou não acontece, e os casos de corrupção se repetem, ou seja, não conseguimos preveni-los (Olivieri, 2011, p. 76).

É observável que, entre as várias estratégias utilizadas para o combate à corrupção, o estudo científico se afigura como uma importante forma de compreensão da corrupção, bem como para o apontamento de soluçóes para o seu enfrentamento. Segundo Huili Zhang, An e Zhong (2019), o problema da corrupção tem sido foco de acadêmicos e profissionais ${ }^{3}$. Porém, como afirma GansMorse, (2018), falta avaliação empírica rigorosa para a maioria das políticas anticorrupção comumente prescritas.

Com efeito, em uma busca na base de dados de produção científica internacional Scopus, a partir dos termos conjuntos de pesquisa "police AND corruption", retornaram como resultado 916 artigos. A partir dessa exploração inicial, foi criada uma rede de conceitos (Figura 1) com base na análise dos 916 artigos, em software de elaboração de cenários conceituais (VosViewer), em que foram comparadas as 2577 palavras-chave dos artigos, sendo que 51 palavras se repetem pelo menos nove vezes ${ }^{4}$.

3 As instituições policiais de Hong Kong eram vistas como uma das mais comuns de ocorrer casos de corrupção, superando, neste item, inclusive, a soma de todos os outros órgãos governamentais juntos, entre os anos de 1952 e 1973 (Manion, 1996).

4 Com um número de repetições de dez vezes, a palavra-chave "brazil” é excluída, e por isso foi rodado o mapa com nove repetições e 51 palavras atendendo a esse critério. 


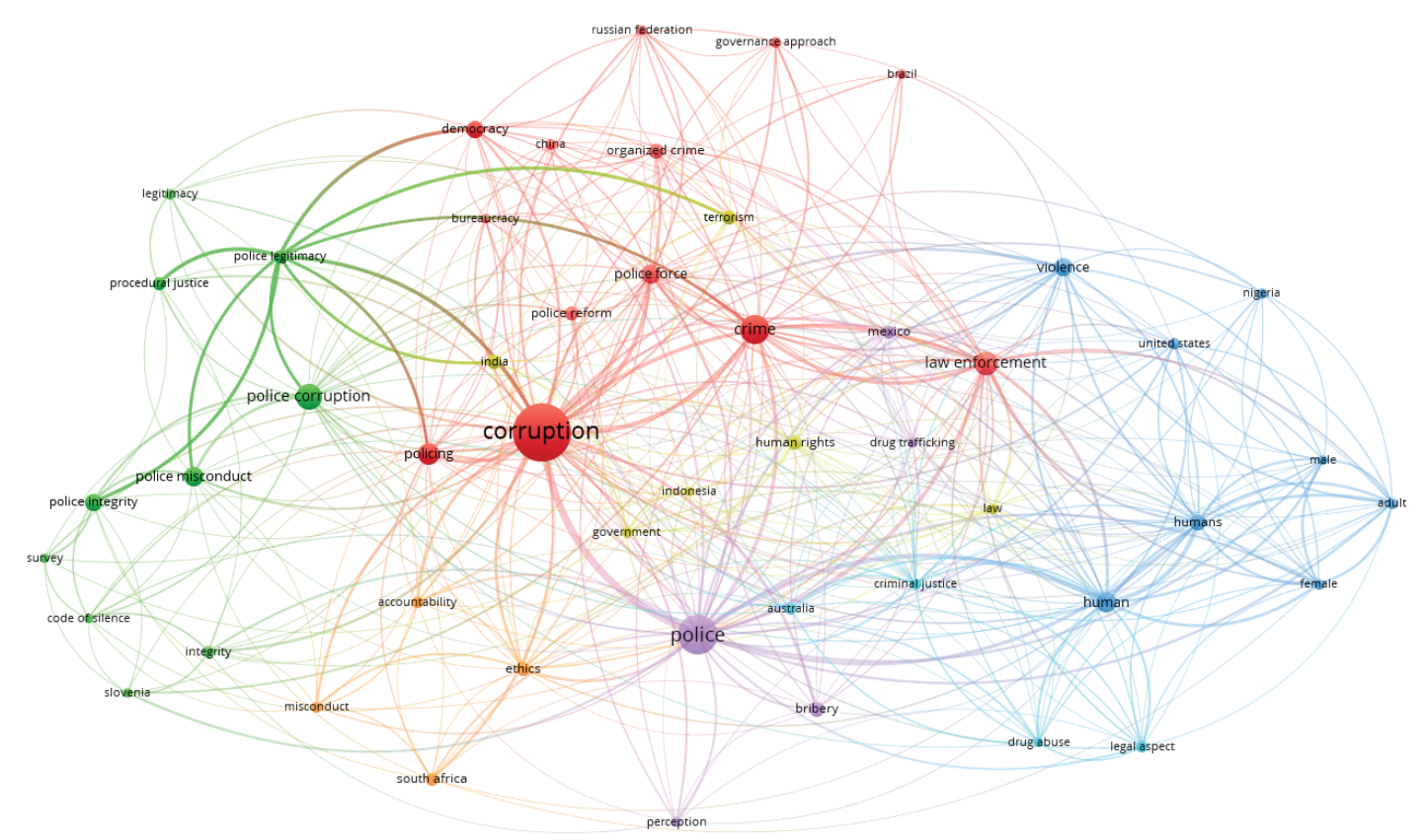

Figura 1: cenário conceitual da literatura disponível na base de dados Scopus, extraída em 29.10.2020.

No mapa da rede de palavras-chave, o tamanho do círculo revela maior quantidade de repetições da palavra dentre os 916 artigos e a espessura da linha revela a maior frequência de citações conjuntas entre as mesmas palavras. Esse mapa distingue a formação de quatro clusters principais: um primeiro em torno do conceito de corrupção (vermelho); um segundo em torno do conceito de polícia (púrpura); um terceiro em torno dos conceitos de humanidades (azul); e um quarto e último em torno do conceito de corrupção da polícia (verde).

Os países com o mesmo número mínimo de nove repetições são: Brasil, China, Eslovênia, Nigéria, Indonésia, Rússia, Índia, África do Sul e Estados Unidos da América. A palavra-chave "Brazil" aparece na periferia do cluster vermelho relacionada diretamente com as palavras: violência, aplicação da lei, crime, reforma da polícia, força policial e corrupção.

Com exceção da relação entre "Brazil" e "violence" (cluster azul), todas as demais palavras relacionadas à palavra-chave "Brazil" pertencem ao cluster vermelho da corrupção, o que pode indicar toda a diversidade de temáticas relacionadas com a corrupção (presentes nos demais clusters) que os estudos sobre a corrupção e polícia no Brasil não abordam. 
A segunda figura (Figura 2) revela a mesma rede organizada pelo ano de publicação dos artigos. As palavras-chave que aparecem em amarelo se referem aos artigos mais recentes nesse cenário conceitual. Evidencia-se que legitimidade policial, justiça processual, integridade policial, crime organizado e suborno são temáticas mais contemporâneas no estudo de polícia e corrupção. A palavra-chave "Brazil", por sua vez, não se relaciona com estas, reforçando a evidência de que essas esferas de desenvolvimento do campo de estudo não estão sendo alcançadas.

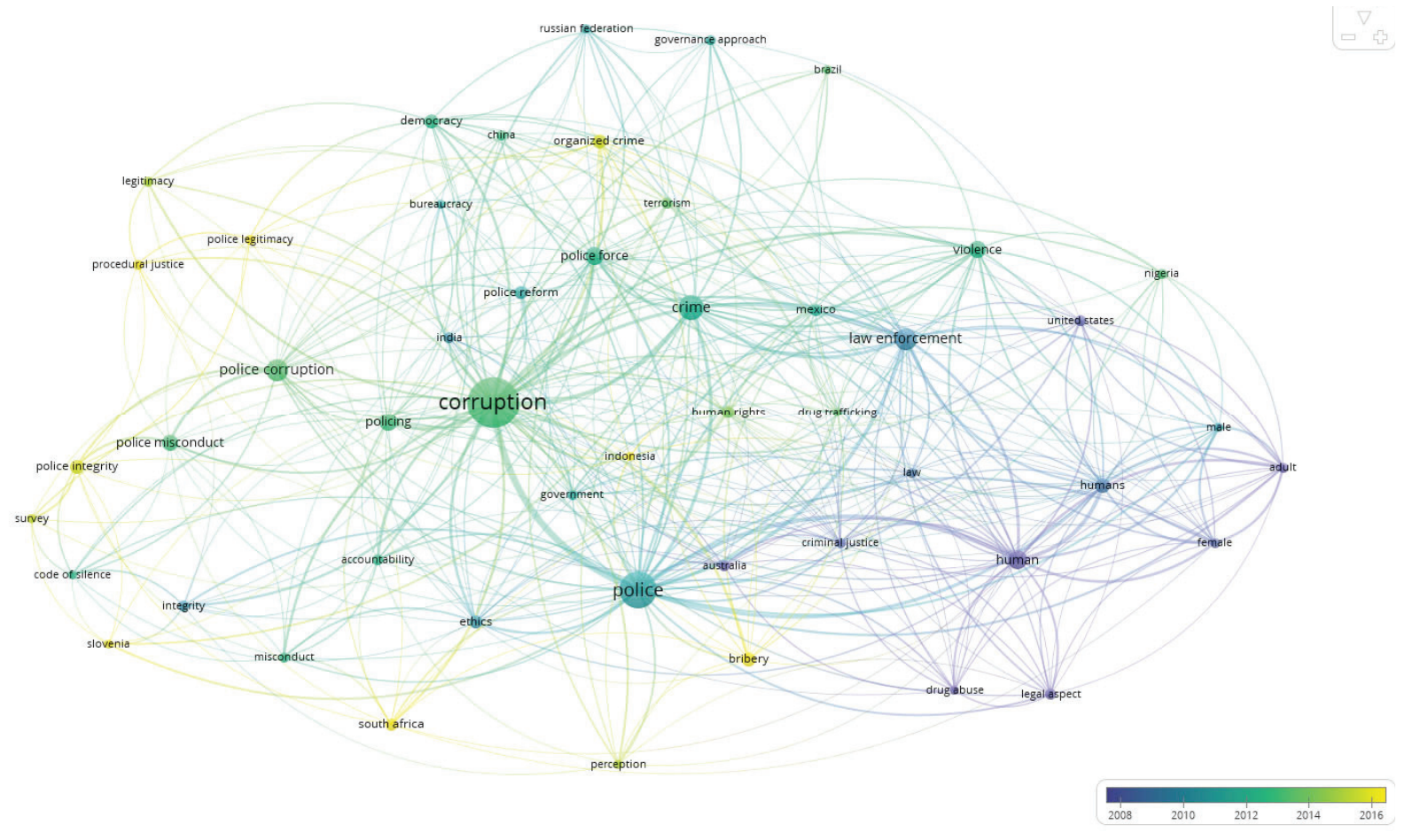

Figura 2: cenário conceitual da literatura disponível organizado por ano de publicação.

Tendo em vista as lacunas indicadas através dos cenários conceituais traçados, este trabalho pode ser enquadrado como um estudo de caso, no qual a Polícia Federal do Brasil, a partir de ações tomadas para a apuração e punição de servidores por desvio de conduta, conformará o objeto de estudo. Com base na literatura, será feita análise com relação ao órgão citado, apontando sua função vertebradora no combate à corrupção pública, compreendida esta função, conforme Rezzoagli (2015), como aquela que lhe é própria e que nenhum outro órgão poderia realizar da mesma forma e com a mesma garantia de efetividade. Além disso, serão reunidos e exibidos dados do Poder Executivo Federal do Brasil relativos à expulsão de servidores por atos de 
corrupção, juntamente com números de casos de corrupção, em nível interno, que levaram à expulsão de servidores da Polícia Federal entre os anos de 2003 aos dias atuais, de modo a permitir, ainda que breve, um exame comparativo pelo resultado.

A seguir, tecemos breves comentários sobre o conceito de corrupção, sobre a instituição Polícia Federal, algumas operações desencadeadas e o resultado das mesmas referente à punição de servidores por desvio de conduta.

\section{Breve Análise do Conceito de Corrupção}

Segundo Prasad, Martins da Silva e Nickow (2018), a literatura acadêmica sobre corrupção se desenvolveu em disciplinas separadas. Cada uma produziu insights importantes, mas cada uma delas também enxergou algumas limitações cruciais. Estes mesmos autores afirmam que qualquer mudança com relação aos níveis de corrupção deve superar três desafios: primeiro, a corrupção persiste porque as pessoas precisam se envolver em corrupção para atender as suas necessidades, ao que denominaram de desafio dos recursos; segundo, a corrupção persiste porque há incerteza sobre o que constitui um presente e o que constitui um suborno, bem como há confusão entre privado e público, ao que denominaram de desafio de definição; terceiro, a corrupção persiste por causa da pressão por comportamentos considerados morais, de acordo com critérios alternativos, como cuidar de seus parentes ou enfrentar legados de racismo e opressão, ao que denominaram de desafio alternativo das moralidades.

Como pode ser observado, entender o que é corrupção ainda conforma um desafio e os limites dessa compreensão nem sempre são muitos claros. A depender do campo de aplicação, é possível encontrar variações. Exemplo disso pode ser revelado no campo jurídico, em especial, no âmbito do Direito Penal, cuja rigidez e clareza de seus tipos se traduzem em garantias tuteladas pela Ordem Jurídica para a aplicação de uma pena.

Nessa seara, a corrupção não se limita ou se enclausura nos tipos penais que carregam seu nome, ou seja, corrupção é diferente de 
crime de corrupção. O sentido de corrupção, portanto, desborda desse campo, podendo encontrar também significação em diversos outros campos como, por exemplo, o moral, o psicológico e o sociológico.

Mais uma vez, a título ilustrativo, trazemos um conceito multidimensional apresentado por Miranda (2018), para quem:

A corrup̧̧ão é o pagamento ilegal (financeiro ou não) para a obtenção, aceleração ou para que haja ausência de um serviço feito por um funcionário público ou privado. A motivação da corrupção pode ser pessoal ou politica tanto para quem corrompe quanto para quem é corrompido.

À semelhança do conceito apresentado por Andvig (2004), é também possível identificar os elementos de transgressão e obtenção de vantagem.

Embora não seja o propósito deste trabalho analisar com profundidade o fenômeno da corrupção em variadas dimensões, mostra-se oportuno, ainda que de modo breve, realçar sua relação, no campo de observação da corrupção na esfera pública, com sistemas hierarquizados. Nesse sentido, Fath e Kay (2018) sugerem a existência de uma percepção de pessoas quanto à associação de hierarquia organizacional à corrupção. Para esses autores, essas pessoas esperam que mais corrupção se manifeste entre os funcionários de organizações relativamente mais hierarquizadas e julgam que uma organização com histórico de corrupção tenha maior probabilidade de ser hierarquizada do que uma organização sem hierarquia.

Para esses autores, a crença leiga de que hierarquia e corrupção estão conectadas é guiada por duas suposições relacionadas: (i) quanto mais hierarquizada for uma organização, mais provável é que seus funcionários sejam competitivos entre si; e (ii) quando os funcionários são mais competitivos uns com os outros, o mais provável é que eles sejam corruptos.

Nekovee e Pinto (2019), variando sistematicamente quatro parâmetros organizacionais relacionados à cultura, ou seja, estrutura organizacional, localização de "maçãs podres", propensão dos funcionários a se corromperem ("probabilidade de corrupção") e número de delatores, concluíram que em organizações com estruturas mais pla- 
nas, a corrupção permeia a organização em um valor limite mais baixo de probabilidade de corrupção em comparação com aquelas com estruturas mais altas.

A título ilustrativo, um dos casos emblemáticos de luta contra a corrupção se deu em Hong Kong, em meados dos anos 70, tratando-se de um audacioso exemplo de intromissão governamental no combate à corrupção, que obteve êxito nas suas ações e tornou-se referência para a elaboração de políticas em diversos outros países. Nesse caso, foram utilizados três elementos-chave, visando a compreender o êxito e limitações quando da tentativa de erradicação endêmica: compromisso credível dos líderes, cultura da corrupção e contexto político e econômico (MANION, 1996).

O caso citado ficou conhecido internacionalmente como "Incidente Godber", no qual Peter Godber, policial em Hong Kong, segundo apurado, aceitava subornos de policiais de patentes inferiores, formando uma organização criminosa. Godberg, ao final, fugiu de Hong Kong quando os atos de corrupção foram revelados. O caso foi transformado em símbolo da corrupção policial, complacência e impotência por parte das autoridades governamentais, ocasionando, em momento posterior, uma reação do governo de Hong Kong contra a corrupção e sua impunidade. Entendeu-se, portanto, que era necessário criar um organismo autônomo de combate à corrupção para que pudesse efetivamente alcançar os casos de corrupção e, devidamente, puni-los (MANION, 1996).

Filgueiras (2009, p. 02), menciona que

Um dos traços caracteristicos do senso comum no Brasil é que o brasileiro típico tem um caráter duvidoso e que, a princípio, não se nega a levar algum tipo de vantagem no âmbito das relaçôes sociais ordinárias. Por isso, vários indicadores de confiança apontam o Brasil como um pais onde a desconfiança impera.

É possível que essa assertiva encontre relação como o que Faoro (apud FILGUEIRAS, 2009), em obra seminal "Os Donos do Poder", denominou de patrimonialismo, que realça um hibridismo ou confusão entre o que é público e o que é privado. 
Abordando formas de diminuir os níveis de corrupção, Amundsen (1999) aponta medidas em quatro níveis: externas ou controle internacional, controle executivo, internas ou controle institucional e controle democrático. $\mathrm{O}$ controle internacional ocorre, por exemplo, quando o Banco Mundial pressiona governos a lutar contra a corrupção como parte de seus acordos. O controle executivo (ou "controle de cima" - control from above) demanda necessariamente vontade política para que ocorra, passando por campanhas de moralização, reformas institucionais e restrições aos departamentos subordinados. $\mathrm{O}$ controle interno ou institucional (control from within) é feito dentro da burocracia, passando por controles administrativos e sistemas executivos. E o controle democrático (control from below) inclui os freios e contrapesos da democracia, a separação de poderes, o devido processo legal, a independência do Legislativo e do Judiciário, dentre vários outros. Neste artigo avaliamos dados relativos ao controle interno da corrupção, verificando ações efetivamente realizadas pela Polícia Federal para combater desvios ocorridos envolvendo seus membros.

\section{MÉTOdo}

O método da presente pesquisa consiste em estudo de caso único (YIN, 2015) sobre a Polícia Federal do Brasil, a partir de informações em fontes abertas (mídia) em comparação com dados oficiais fornecidos pela Controladoria Geral da União. Com efeito, o estudo de caso se torna uma estratégia metodológica relevante quando se unem duas características: o contexto é relevante para a compreensão do fenômeno; e quando é possível se valer de diferentes métodos de coleta de dados em variadas fontes, de maneira a completar um quadro de evidências por diferentes perspectivas (YIN, 2015), conforme será descrito.

Inicialmente, foram extraídos dados secundários, em fontes abertas disponibilizadas pela Controladoria Geral da União - CGU, relativos a penalidades aplicadas a agentes públicos do Poder Executivo Federal, no período de 2003 a 2019, em decorrência de atos de corrupção. Para os fins deste trabalho, atos de corrupção foram compreendidos como transgressões disciplinares tipificadas na Lei . $^{\circ}$ 
4.878/65 (art. 43, IX e LXI) ${ }^{5}$, que dispõe sobre o regime jurídico peculiar dos policiais civis da União e do Distrito Federal, e na Lei n. ${ }^{\circ}$ 8.112/90 (art. 117, IX e XVI ${ }^{6}$ e art. 132, IV, X e XI) ${ }^{7}$, que trata do regime jurídico dos servidores público civis da União, das autarquias e das fundações públicas federais. Posteriormente, foi utilizado filtro de pesquisa, de modo a serem extraídos dados relativos, especificamente, a servidores da Polícia Federal.

Criado pela então CGU, o Painel de Corregedorias (paineis. cgu.gov.br/corregedorias/index.htm) se integra ao conjunto de ferramentas do governo federal voltadas à transparência, dentro de uma política de dados abertos. Seu conteúdo apresenta informações sobre penalidades aplicadas a servidores públicos do Poder Executivo federal, bem como a empresas e entidades.

De outro modo, também foram coletadas informações em fontes abertas, relativas a prisões de policiais federais envolvidos em casos de corrupção (podendo envolver os crimes de corrupção passiva, concussão, peculato ou outros), no mesmo período, divulgadas em sítios eletrônicos de notícia mais acessados no Brasil (MEIRELES, 2018), disponíveis na internet.

Com base nesses parâmetros, foram realizadas buscas textuais nos seguintes sítios eletrônicos de notícias, por meio de buscador disponível (Google):

a) portal de notícias do grupo Globo (www.globo.com);

b) portal de notícias UOL (www.uol.com.br);

\footnotetext{
5 Art. 43. São transgressões disciplinares:

IX - receber propinas, comissões, presentes ou auferir vantagens e proveitos pessoais de qualquer espécie e, sob qualquer pretexto, em razão das atribuições que exerce;

LXI - cobrar carceragem, custas, emolumentos ou qualquer outra despesa que não tenha apoio em lei.

6 Art. 117. Ao servidor é proibido:

IX - valer-se do cargo para lograr proveito pessoal ou de outrem, em detrimento da dignidade da função pública;

XVI - utilizar pessoal ou recursos materiais da repartição em serviços ou atividades particulares;

7 Art. 132. A demissão será aplicada nos seguintes casos:

IV - improbidade administrativa;

$\mathrm{X}$ - lesão aos cofres públicos e dilapidação do patrimônio nacional;

XI - corrupção;
} 
c) portal de notícias Metrópoles (www.metropoles.com).

Outros portais e agências consultados (complementares):

a) Jornal Folha de São Paulo (www.folha.uol.com.br);

b) Jornal O Estado de São Paulo (www.estadao.com.br);

c) Canal BBC - Brasil (www.bbc.com/portuguese);

d) Google notícias (news.google.com.br);

e) Portal de Notícias Terra (www.terra.com.br);

f) Portal de Notícias R7 (Grupo Record, www.r7.com).

As buscas textuais realizadas nos endereços eletrônicos indicados acima levaram em conta as palavras-chaves: ["policial federal" e "preso"] e [policial federal preso], no período compreendido entre os anos de 2010 a 2019. Foram consideradas, ainda, nas pesquisas, quando disponível, os 50 primeiros resultados (ou seja, os resultados tidos como mais relevantes pelos algoritmos das próprias páginas com os termos pesquisados).

Por fim, optou-se pela pesquisa relacionada à prisão de policiais envolvidos em casos de corrupção, por ser maior a probabilidade de divulgação na mídia em relação a casos onde houve responsabilização, porém, não houve a prisão. Como consequência de tal escolha metodológica, fica evidente, de antemão, que o número de servidores responsabilizados em casos de corrupção é maior que o número de presos (já que nem todos os responsabilizados chegam a ser efetivamente presos durante o processo investigatório). Contudo, a prisão de policiais federais por corrupção foi considerada como fenômeno relevante a ser observado em razão do caráter pedagógico (efeito psicológico positivo em relação ao combate à corrupção internamente).

Os resultados foram compilados e são apresentados no próximo tópico. 


\section{Números de Combate À Corrupção INSTITUCIONAL}

Segundo histórico constante de seu Plano Estratégico de 2010/20228, a Polícia Federal tem sua origem remota no período do império, com a Intendência-Geral de Polícia da Corte e do Estado do Brasil, criada por D. João VI (no ano de 1808). De modo próximo, em 1944, a Polícia Civil do Distrito Federal foi transformada em Departamento Federal de Segurança Pública - DFSP, já incluindo serviços "de polícia e segurança pública no Distrito Federal e, em âmbito nacional, os de polícia marítima, aérea e segurança de fronteiras" (Polícia Federal, 2019). A Constituição Federal de 1967 começou a utilizar a expressão Polícia Federal e a atual Constituição Federal, de 1988, manteve a denominação e a trouxe como órgão integrante da segurança pública (prevista no art. 144, inciso I).

Desse modo, fica bastante claro que esse órgão, que integra a administração direta da União, não foi criado especificamente para a função de combate à corrupção. Porém, acabou ganhando essa função como consequência de suas atribuições de polícia investigativa de crimes com interesse federal, destacando-se, portanto, como órgão criado para aplicação da lei. Essas características aproximam a Polícia Federal do modelo de instituições de aplicação da lei (law enforcement type institutions) definido pela Organização para Cooperação e Desenvolvimento Econômico - OCDE (OECD, 2008), que ao lado de outras instituições nacionais, possui relevante papel no combate à corrupção na administração pública federal, conforme será detalhado na próxima seção.

Por outro lado, verifica-se que deriva do texto da Constituição Federal brasileira a função principal (vertebradora) da Polícia Federal, que é conformada na atuação como polícia judiciária da União. $\mathrm{O}$ mesmo texto prevê como sendo atribuição da Polícia Federal a apuração das infrações penais contra a ordem política e social ou em detrimento de bens, serviços e interesses da União ou de suas entidades autárquicas e empresas públicas, assim como outras infrações cuja prática tenha repercussão interestadual ou internacional e exija repressão uniforme, segun-

8 Disponível em: http://www.pf.gov.br/institucional/planejamento-estrategico e acessado em 14/04/2019. Acesso em: 14 abr. 2019. 
do se dispuser em lei; prevenção e repressão do tráfico ilícito de entorpecentes e drogas afins, o contrabando e o descaminho, sem prejuízo da ação fazendária e de outros órgãos públicos nas respectivas áreas de competência; exercer as funções de polícia marítima, aérea e de fronteiras; e exercer, com exclusividade, as funções de polícia judiciária da União (Constituição, 1988). Ao lado das funções mencionadas anteriormente, a Polícia Federal realiza, ainda, desde o monitoramento de atividades criminosas, prisões, investigação de crimes e depoimentos em tribunais, dentre outras atividades de suma importância, precisando, ainda, dar uma resposta rápida aos casos de emergência relatados por pessoas, bem como nas investigações que atuem (Kulachai, 2017). Cabe à PF apurar, dentre outros, os crimes de corrupção de competência da União, ou seja, possui como função vertebradora a apuração de crimes e infrações penais cometidos contra a União e também suas empresas e fundações públicas, cabendo destacar o combate à corrupção.

O destaque da Polícia Federal no combate à corrupção no Brasil, como agência anticorrupção de aplicação da lei, pode ser vislumbrado, por exemplo, pela execução da denominada "Operação Lava Jato” em suas diversas fases, que foi empreendida pela Polícia Federal com o apoio de outras instituições.

Por outro lado, sob aspectos orgânicos, a força de trabalho da Polícia Federal é constituída por servidores policiais e não-policiais e outros colaboradores. O contingente de servidores policiais é formado pelos ocupantes dos cargos de Delegado de Polícia Federal, Perito Criminal Federal, Agente de Polícia Federal, Escrivão de Polícia Federal e Papiloscopista Policial Federal, cujas carreiras são escalonadas em quatro classes - terceira, segunda, primeira e especial. Já os servidores não-policiais integram a carreira técnico-administrativa em um denominado Plano Especial de Cargos - PEC/DPF. Além dos servidores técnico-administrativos de seu próprio quadro, a PF também é integrada por agentes públicos de fora de seu quadro, a exemplo, de servidores anistiados, cedidos, dentre outros e também por servidores contratados.

Segundo dados abertos estatísticos oficiais disponíveis no painel estatístico de pessoal do governo federal ${ }^{9}$, para o mês de janeiro de 2019, a força de trabalho da Polícia Federal, formada por servidores

9 Disponível em: https://www.painel.pep.planejamento.gov.br. Acesso em: 16 nov. 2020. 
ativos permanentes, foi estimada em 12.838 servidores, incluídos nesse cômputo servidores policiais e não-policiais.

Ainda sobre as características da Polícia Federal, é destaque que o acesso aos seus quadros é realizado por meio de concurso público, que é composto de diversas fases e exige preparação técnica, física e psicológica. Segundo dados fornecidos pela Coordenação de recrutamento e Seleção - Corec/DG/PF ${ }^{10}$, o último concurso realizado no ano de 2018 para cargos policiais contou com a participação de 147.744 (cento e quarenta e sete mil setecentos e quarenta e quatro) candidatos.

Tendo compreendido aspectos institucionais e seus desafios, são exibidos a seguir dados sobre corrupção na Administração Pública Federal e, mais precisamente, no Poder Executivo federal, que foram extraídos, em fonte aberta, do Painel de Corregedorias ${ }^{11}$. A Figura 3 apresenta comparação entre expulsões e reintegrações de servidores do Poder Executivo federal entre os anos de 2003 e 2019. É possível observar que no Poder Executivo federal foram expulsos 16.313 servidores no período, sendo 407 servidores da Polícia Federal.

Servidores do Poder Executivo federal

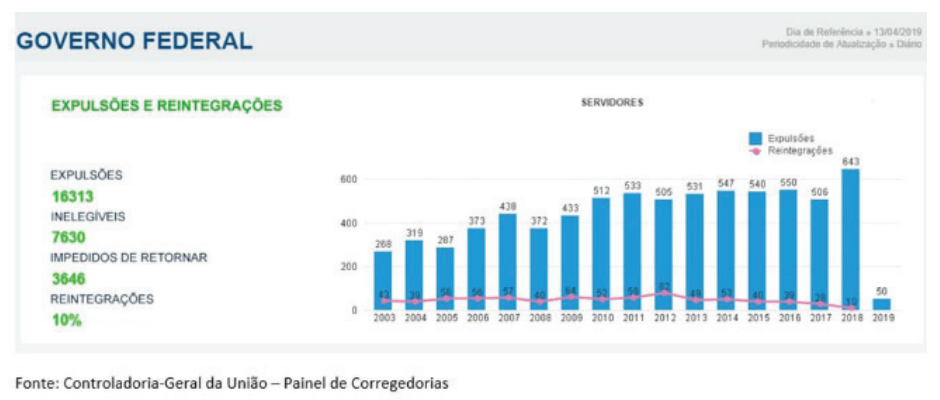

Servidores da Polícia Federal

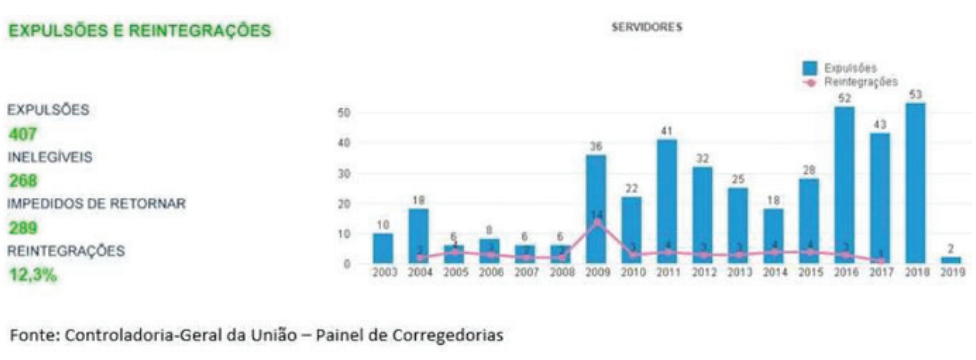

Figura 3: comparação entre expulsões e reintegrações de servidores do Poder Executivo federal de 2003 a 2019.

10 Processo SEI 08280.008095/2019-31.

11 Disponível em: http://paineis.cgu.gov.br/corregedorias/index.htm. Acesso em: 17 nov. 2020. 
Conforme é possível observar, por meio da comparação dos gráficos acima disponibilizados pela CGU, o comportamento do crescimento de expulsões na Polícia Federal é mais acentuado e significativo no período demonstrado. A Tabela 1 apresenta análise da variação percentual numérica a cada ano e assinala, em amarelo, as variações maiores que 30\%, evidenciando que na Polícia Federal isso ocorre em quantidade muito superior. Observando a variação acumulada de crescimento percentual, fica bem evidente que, ao final do período de 2003 a 2018, o número de expulsões no Poder Executivo teve um crescimento percentual acumulado de expulsões de $140 \%$, enquanto a Polícia Federal teve crescimento acumulado de $430 \%$, demonstrando, assim, um impacto de expulsões significativamente maior nesta instituição, o que enseja reflexões sobre os impactos desta situação na gestão das instituições e sua entrega de resultados. Com os dados foi delineado o gráfico da Figura 4, que apresenta o aumento percentual no número total de demissões em relação ao número de demissões no início da observação (ano de 2003).

\begin{tabular}{|c|c|c|c|c|}
\hline \multirow[b]{2}{*}{ Ano } & \multicolumn{2}{|c|}{ Poder Executivo Federal } & \multicolumn{2}{|c|}{ Polícia Federal } \\
\hline & $\begin{array}{l}\text { Número de } \\
\text { expulsões }\end{array}$ & $\begin{array}{l}\text { Crescimento per- } \\
\text { centual em relação } \\
\text { ao ano anterior }\end{array}$ & $\begin{array}{l}\text { Número de } \\
\text { expulsões }\end{array}$ & $\begin{array}{l}\text { Crescimento } \\
\text { percentual em } \\
\text { relação ao ano } \\
\text { anterior }\end{array}$ \\
\hline 2003 & 268 & & 10 & \\
\hline 2004 & 319 & $19 \%$ & 18 & $80 \%$ \\
\hline 2005 & 287 & $-10 \%$ & 6 & $-67 \%$ \\
\hline 2006 & 373 & $30 \%$ & 8 & $33 \%$ \\
\hline 2007 & 438 & $17 \%$ & 6 & $-25 \%$ \\
\hline 2008 & 372 & $-15 \%$ & 6 & $0 \%$ \\
\hline 2009 & 433 & $16 \%$ & 36 & $500 \%$ \\
\hline 2010 & 512 & $18 \%$ & 22 & $-39 \%$ \\
\hline 2011 & 533 & $4 \%$ & 41 & $86 \%$ \\
\hline 2012 & 505 & $-5 \%$ & 32 & $-22 \%$ \\
\hline 2013 & 531 & $5 \%$ & 25 & $-22 \%$ \\
\hline 2014 & 547 & $3 \%$ & 18 & $-28 \%$ \\
\hline 2015 & 540 & $-1 \%$ & 28 & $56 \%$ \\
\hline 2016 & 550 & $2 \%$ & 52 & $86 \%$ \\
\hline
\end{tabular}




\begin{tabular}{c|c|c|c|c}
\hline 2017 & 506 & $-8 \%$ & 43 & $-17 \%$ \\
\hline 2018 & 643 & $27 \%$ & 53 & $23 \%$ \\
\hline & & $140 \%$ & & $430 \%$
\end{tabular}

Figura 4: aumento percentual no número de demissões (em relação ao ano de 2003).

Foram ainda obtidos outros gráficos que tipificam melhor as expulsões do Poder Executivo federal. Na Figura 5 é possível observar o número de processos instaurados e concluídos em relação à conduta de servidores. Da figura é possível observar que o número de processos mostra aparente declínio, embora o número de expulsões continue em crescimento (vide Figura 4).

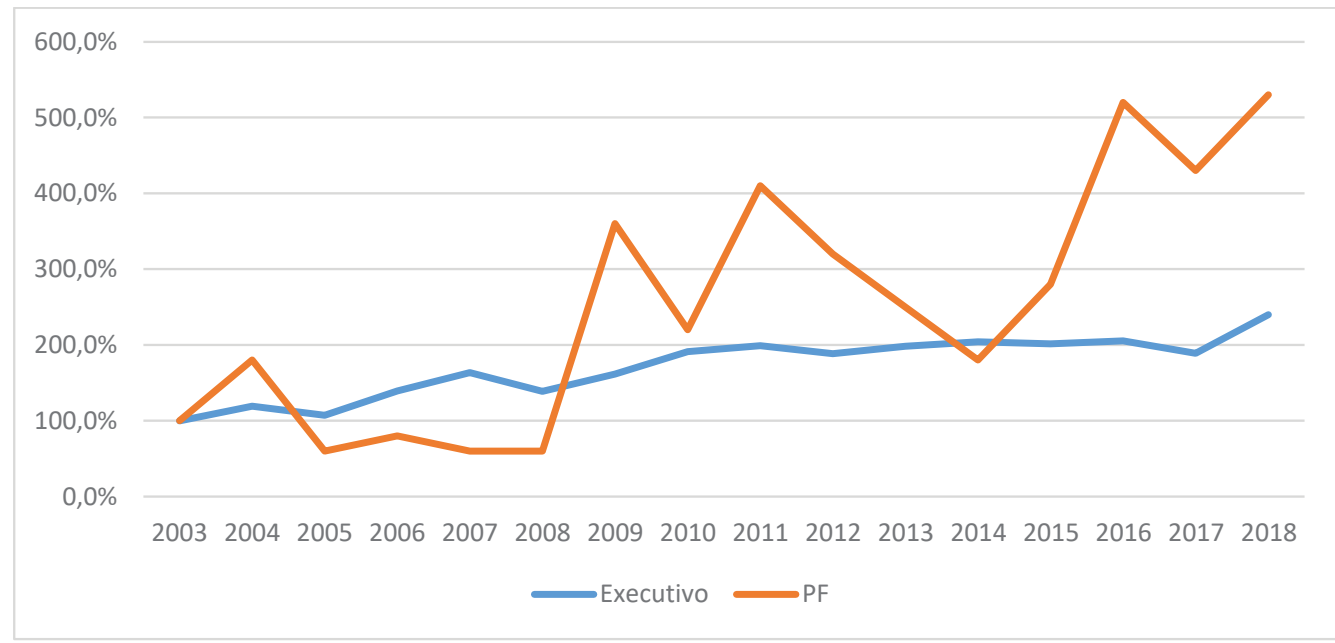

Figura 5: comparativo de processos instaurados e concluídos no Poder Executivo federal.

Quanto à fundamentação dos casos de expulsão, a Figura 6 apresenta que 4.895 servidores foram expulsos por questóes relacionadas à corrupção, bem como 1.759 expulsões foram em decorrência de “abandono, inassiduidade ou acumulação", 207 por “desídia” e 9.369 expulsões por outros motivos. 

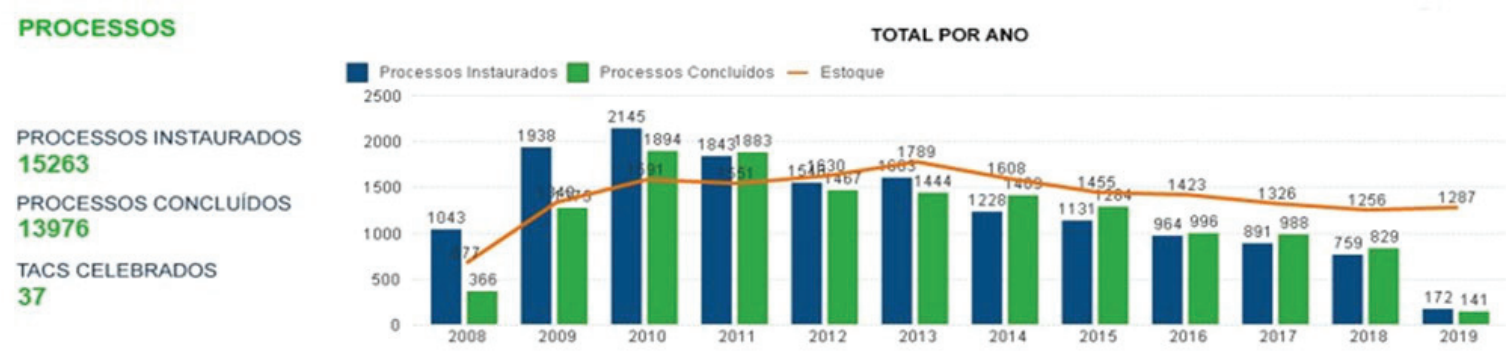

Fonte: Controladoria-Geral da União - Painel de Corregedorias

Figura 6: tipo de expulsão no Poder Executivo federal.

Observou-se ainda o quantitativo de casos que geraram demissão ou cassação de aposentadoria, informação constante da Figura 7 , na qual é possível ver que das 407 expulsões de servidores da Polícia Federal, 350 geraram demissão e 57 geraram cassação de aposentadoria.

EXPULSĀO POR:

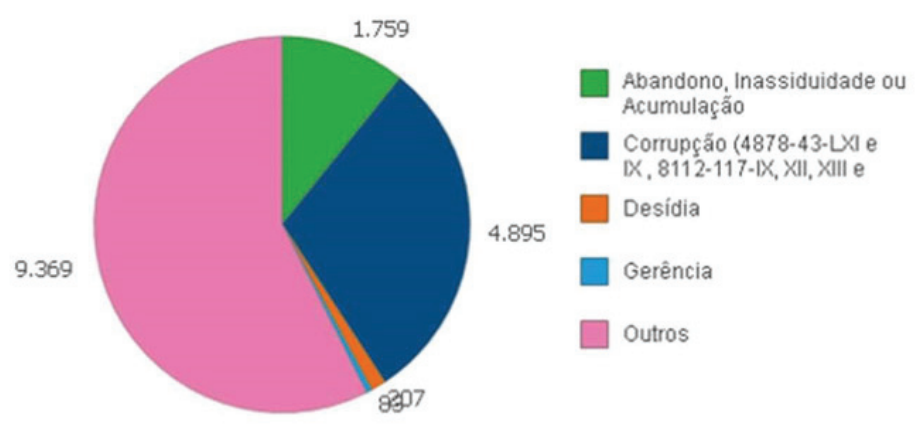

Fonte: Controladoria-Geral da União - Painel de Corregedorias

Figura 7: efeitos da expulsão de servidores da Polícia Federal.

Com intuito de qualificar melhor as expulsões na Polícia Federal, apresenta-se na Tabela 2 uma sistematização das publicações referentes às seguintes prisões de policiais federais envolvidos em casos de corrupção. Na tabela foram incluídas informações sobre a Unidade da Federação onde ocorreu o caso, o ano e um breve resumo da ação policial respectiva. 
Tabela 2: publicações a respeito de expulsões de servidores da Polícia Federal

\begin{tabular}{|c|c|c|}
\hline UF & Ano & Contexto \\
\hline PR & 2003 & $\begin{array}{l}\text { Operação Sucuri: } 22 \text { policiais federais presos na Operação Su- } \\
\text { curi, acusados de corrupção na fronteira do Brasil com o Para- } \\
\text { guai em Foz do Iguaçu, quatro servidores da Receita Federal e } \\
\text { dois policiais rodoviários federais envolvidos em um esquema } \\
\text { de facilitação na travessia de automóveis na fronteira Brasil- } \\
\text {-Paraguai. }\end{array}$ \\
\hline $\mathrm{AP}$ & 2008 & $\begin{array}{l}\text { Diretor Executivo da instituição foi preso sob acusação de ad- } \\
\text { vocacia administrativa e tráfico de influência para beneficiar } \\
\text { empresas no Amapá. }\end{array}$ \\
\hline $\mathrm{RJ}$ & 2008 & $\begin{array}{l}\text { Operação Resplendor: quadrilha que distribuía e revendia com- } \\
\text { bustível ilegalmente no Sul Fluminense. O esquema criminoso } \\
\text { incluía o acobertamento policial criminoso a atividades comer- } \\
\text { ciais ilícitas ou desleais à concorrência, especialmente a compra, } \\
\text { distribuição e revenda clandestina de combustíveis, muitas vezes } \\
\text { adulterados e com fraudes fiscais. }\end{array}$ \\
\hline MS & 2011 & $\begin{array}{l}\text { Policial federal preso acusado de receber propina para regulari- } \\
\text { zar a situação de estrangeiros ilegais no país. }\end{array}$ \\
\hline $\mathrm{RO}$ & 2012 & $\begin{array}{l}\text { Policial federal de Rondônia foi preso no Paraná trazendo veí- } \\
\text { culo contendo entorpecentes e fuzis oriundos do Paraguai. Su- } \\
\text { postamente o policial teria sido cooptado para realizar o trans- } \\
\text { porte. }\end{array}$ \\
\hline SP & 2013 & $\begin{array}{l}\text { Policial federal supostamente levantava informações contra co- } \\
\text { merciante e os ameaçava de prisão caso não passassem propina } \\
\text { ao policial. }\end{array}$ \\
\hline PR & 2014 & $\begin{array}{l}\text { Policial federal preso na Operação Lava-Jato e condenado por } \\
\text { lavagem de dinheiro. }\end{array}$ \\
\hline PR & 2016 & $\begin{array}{l}\text { Policial federal preso por supostamente fazer parte de quadri- } \\
\text { lha que facilitava o contrabando/descaminho de mercadorias } \\
\text { oriundas do Paraguai. }\end{array}$ \\
\hline $\mathrm{RJ}$ & 2016 & $\begin{array}{l}\text { A ação foi contra grupo que atuava no tráfico de entorpecentes, } \\
\text { tendo sido presas várias pessoas, inclusive policial federal que } \\
\text { seria informante do grupo preso. }\end{array}$ \\
\hline $\mathrm{RJ}$ & 2016 & $\begin{array}{l}\text { Policial foi condenado a } 17 \text { anos e } 2 \text { meses de prisão por cor- } \\
\text { rupção e foi preso em casa na praia no estado do Rio Grande } \\
\text { do Norte. }\end{array}$ \\
\hline SP & 2016 & $\begin{array}{l}\text { Três delegados presos sob acusação de exigir pagamento de pro- } \\
\text { pina para deixar de realizar investigações sobre crimes previden- } \\
\text { ciários. }\end{array}$ \\
\hline
\end{tabular}




\begin{tabular}{|c|c|c|}
\hline ES & 2017 & $\begin{array}{l}\text { Em esquema criminoso para extração ilegal de granito várias } \\
\text { pessoas foram presas, inclusive um policial federal suspeito de } \\
\text { participar da quadrilha, onde teria praticado o crime de corrup- } \\
\text { ção passiva. }\end{array}$ \\
\hline PR & 2017 & $\begin{array}{l}\text { Delegado da PF preso em Londrina - Paraná, sob acusação de } \\
\text { receber propina de comerciante local para não o responsabilizar } \\
\text { criminalmente. }\end{array}$ \\
\hline PR & 2017 & $\begin{array}{l}\text { Delegado foi preso em flagrante enquanto alegadamente dividia } \\
\text { dinheiro oriundo de propina e extorsão entre empresários da ci- } \\
\text { dade de Londrina. }\end{array}$ \\
\hline SP & 2017 & $\begin{array}{l}\text { Operação Proteína: a investigação apurou a fabricação, impor- } \\
\text { tação e distribuição ilegal de medicamentos, principalmente } \\
\text { anabolizantes, em seis estados. Entre os presos está um policial } \\
\text { militar, que foi levado para a sede da Polícia Federal pela Cor- } \\
\text { regedoria. Os outros dois são agentes em São Paulo, da própria } \\
\text { PF. Todos são investigados pelos crimes de contrabando, falsifi- } \\
\text { cação de medicamentos, corrupção, tráfico de drogas e organi- } \\
\text { zação criminosa. }\end{array}$ \\
\hline MS & 2018 & $\begin{array}{l}\text { Operação Carontes: prisão de um policial federal, um servidor } \\
\text { administrativo e um contratado da PF, além de dois integrantes } \\
\text { de empresas de turismo, operação realizada pela Delegacia de } \\
\text { Corumbá-MS. }\end{array}$ \\
\hline PR & 2018 & $\begin{array}{l}\text { Policial federal preso enquanto supostamente distribuía cigar- } \\
\text { ros contrabandeados do Paraguai que teriam sido apreendidos. }\end{array}$ \\
\hline $\mathrm{RS}$ & 2019 & $\begin{array}{l}\text { Delegado da PF teria aceitado propina para deixar de realizar } \\
\text { investigação em hospital regional em prejuízo ao SUS - Sistema } \\
\text { Único de Saúde. }\end{array}$ \\
\hline $\mathrm{DF}$ & 2020 & $\begin{array}{l}\text { Agente Administrativa da PF estaria vazando informações para } \\
\text { organização criminosa destinada ao tráfico de drogas. Foi presa } \\
\text { e demitida. }\end{array}$ \\
\hline
\end{tabular}

Foram identificadas 18 matérias jornalísticas a respeito da prisão de 20 policiais federais nos últimos dez anos, distribuídas em oito unidades da federação. Assim, chega-se à média de notícias de dois policiais federais presos por ano frente a um contingente de aproximadamente dez mil policiais. Conforme indicado na seção de métodos, os resultados foram buscados com enfoque nos últimos dez anos. Foi incluída notícia a respeito da denominada Operação Sucuri em razão da relevância para o combate à corrupção praticada por policiais federais, tendo sido presos 22 policiais naquela operação. Observando-se, inicialmente, a distribuição por unidades da federação, é possível constatar que o estado com maior quantidade de prisões noticiadas pela 
mídia foi o Paraná (com seis notícias), seguido pelo Rio de Janeiro e São Paulo (com três notícias cada).

Com relação ao Paraná, observa-se que a Operação Sucuri acima mencionada ocorreu naquele estado e foi decorrente justamente da corrupção efetivada para permitir a ocorrência de crimes de contrabando/descaminho pela fronteira terrestre de maior relevância em termos de ocorrências policiais (Foz do Iguaçu e região).

Os estados do Rio de Janeiro e de São Paulo são os maiores centros urbanos do país e, provavelmente, as maiores unidades da Polícia Federal em termos de efetivo, sendo estatisticamente esperável o resultado de maior número de ocorrências em tais regiôes. De outro lado, retomando o contido na literatura, é possível observar que foram realizadas prisões, inclusive, de um diretor do órgão, apontando que, para o combate efetivo à corrupção institucionalizada, é necessária a atuação mesmo nos altos níveis das corporações (PAIVA, 2009).

Para o mês de dezembro de 2019, segundo dados abertos do painel estatístico de pessoal ${ }^{12}$, o Brasil contava com 468.329 (quatrocentos e sessenta e oito mil, trezentos e vinte e nove) servidores ativos permanentes no Poder Executivo federal, incluídos neste cômputo autarquias e fundações federais. Já a Polícia Federal contava com 13.048 (treze mil e quarenta e oito servidores), dos quais, 10.634 (dez mil, seiscentos e trinta e quatro) servidores policiais e 2.414 (dois mil, quatrocentos e catorze) não policiais. Conforme dados da CGU, entre 2003 e 2019, no Poder Executivo federal foram expulsos 4.895 servidores por corrupção (cerca de um expulso a cada 240 servidores atuais), enquanto na PF foram expulsos 315 (cerca de um expulso a cada 31,5 servidores atuais). Isso mostra uma ocorrência cerca oito vezes maior de casos de expulsão de servidores do órgão analisado.

A leitura dos dados de ocorrência de corrupção policial, porém, em razão das limitações da presente pesquisa, não autoriza conclusões quanto ao nível de corrupção nessa organização. Por outro lado, estimula a realização de pesquisas empíricas, que reúnam dados mais profundos e método aplicado, para a satisfação dessa lacuna.

12 Disponível em: https://www.painel.pep.planejamento.gov.br/.Acesso em: 17 nov. 2020. 
De outro modo, comparando com outras modalidades de decisões apontadas pela CGU, na PF foram, proporcionalmente, considerados inelegíveis quatro vezes mais servidores que no Poder Executivo como um todo e 9,5 vezes mais servidores "impedidos de retornar".

Com efeito, é possível que o papel da Polícia Federal no combate à corrupção, seja sob uma perspectiva externa (operações policiais em geral), seja sob uma perspectiva interna (desvios de conduta de servidores), concorra ou influencie o grau de confiança depositado pela população nessa instituição, conforme identifica o Índice de Confiança Social (ICS) medido desde 2009 pelo Instituto Brasileiro de Opinião Pública e Estatística - Ibope, que, no ano de 2019, em um rol de 20 instituições, classificou a Polícia Federal em segundo lugar em grau de confiança, sendo superada somente pela instituição Corpo de Bombeiro (IBOPE, 2019 ${ }^{13}$ ).

\section{Conclusốes}

A Polícia Federal brasileira tem como função essencial a investigação criminal, atuando fortemente em casos de combate à corrupção. Sendo a instituição formada por pessoas, inexoravelmente também está sujeita a ter desvios entre os servidores de seus quadros. A PF teve, em números absolutos, aproximadamente, oito vezes mais servidores expulsos por corrupção em comparação ao Poder Executivo federal, o que indica que o combate à corrupção no órgão recebe tratamento mais rígido do que no Executivo como um todo.

A literatura aponta que a atuação de repressão interna contra casos de corrupção é essencial para que qualquer órgão de combate à corrupção possa ter sucesso nesse mister (AMUNDSEN, 1999). Nesse contexto, a Polícia Federal se legitima, sua atuação interna baliza os servidores na abordagem da corrupção externamente e a torna exemplo a ser seguido pelos demais órgãos do poder público.

O presente artigo foi baseado em notícias divulgadas em fontes abertas a respeito de prisóes de policiais federais envolvidos em casos de corrupção e de dados de expulsão de servidores por atos de corrupção. A primeira limitação se apresenta pela possível ausência de infor-

13 Disponível em: http://177.47.5.246/noticias-e-pesquisas/brasileiro-esta-mais-confiante-nasinstituicoes/. Acesso em: 17 nov. 2020. 
mações acerca de prisões de servidores policiais que, eventualmente, podem não ter sido divulgadas na mídia aberta e, portanto, não estariam abrangidas pela presente pesquisa.

Novas pesquisas poderão coletar, junto à própria instituição ou ao Ministério da Justiça e Segurança Pública (a quem o órgão está subordinado), dados não apenas sobre prisões, mas também casos onde houve a responsabilização (indiciamento) de policiais federais (mesmo que não tenha sido feita a prisão). Outras possibilidades de desenvolvimento de estudos se referem à legitimidade e integridade policial como consequência da rigorosa repressão interna para que se possa acompanhar o cenário mais amplo de estudos do setor. Além disso, pesquisas empíricas também poderão ser realizadas de modo a testar a existência ou não de efeitos preditivos, por exemplo, entre graus de hierarquia e corrupção, além de variáveis demográficas como gênero, tempo de serviço etc., bem como descrever e testar relações entre o número de incidências de expulsão e o nível de corrupção de órgão público.

Carlos Frederico Portella Santos Ribeiro Mestrado Profissional em Administração Pública UNIVERSIDADE DE BRASÍLIA Delegado de Polícia Federal

Joselito de Araujo Sousa Mestrado Profissional em Administração Pública Universidade De BRAsília Delegado de Polícia Federal

Nelson Levy Kneip de Freitas Macedo Mestrado Profissional em Administração Pública UNIVERSIDADE DE BRAsília Delegado de Polícia Federal

Siegrid Guillaumon Dechandt 
Polícia Federal: Função Vertebradora, combate à Corrupção e os Desvios de Conduta...

Pós-Doutorado Na Universidad NaCional deL

LITORAL.

Doutorado e Mestrado em Administração pela

Universidade Federal de Bahia.

Graduação em Administração pela Universidade de

São Paulo.

\title{
Federal Police: Vertebrating Function, Fighting Corruption and Deviations from Police Conduct
}

\begin{abstract}
The article approaches, in a theoretical way, the vertebrating function of the Brazilian Federal Police (PF) in fighting corruption, starting by fighting cases involving its own civil servants. A survey was carried out with the Brazilian Comptroller General (CGU) of data on the punishment of federal civil servants for corruption and other causes. An analysis was also made of news published in major newspapers about federal police arrests for corruption, as a phenomenon resulting from the fight against internal corruption. The comparative results show much greater rigidity with which the Brazilian Federal Police handles cases of internal corruption in relation to the other organs of the Federal Executive Branch, having been expelled, in the period from 2003 to 2019, eight times more servers of the Federal Executive Branch, involvement in cases of corruption, in relation to the general average.
\end{abstract}

KEYwORDS: Corruption. Vertebrating function. Brazilian Federal Police. Civil servant.

\section{Policía Federal: Función Vertebradora, LUCHA CONTRA LA CORRUPCIÓN Y Desviaciones de la Conducta Policial}

\section{RESUMEN}

El artículo aborda, de manera teórica, la función vertebradora de la Policía Federal (PF) en el combate a la corrupción, comenzando por combatir los casos que involucran a sus 
propios funcionarios. Se realizó una encuesta con la Contraloría General de la Federación (CGU) de datos sobre el castigo a los servidores públicos federales por corrupción y otras causas. También se analizaron las noticias publicadas en los principales periódicos sobre detenciones de policías federales por corrupción, como fenómeno derivado de la lucha contra la corrupción interna. Los resultados comparativos muestran mucha mayor rigidez con la que la Policía Federal maneja los casos de corrupción interna en relación a los demás órganos del Ejecutivo Federal, habiendo sido expulsados, en el período de 2003 a 2019, ocho veces más servidores del Ejecutivo Federal, por participación en casos de corrupción, en relación a la media general.

Palabras Clave: Corrupción. Función vertebradora. Policía Federal de Brasil. Empleado estatal.

\section{REFERÊNCIAS}

ABRAHAM, J.; GIOVANI PEA, A. Can proneness to moral emotions detect corruption? The mediating role of ethical judgment based on unified ethics. Kasetsart Journal of Social Sciences, 4-11, 2018. Disponível em: https://doi.org/10.1016/j.kjss.2018.07.013. Acesso em: 29 abr. 2021.

AMUNDSEN, Inge. Political corruption: an introduction to the issues. Chr. Michelsen Institute, 1999.

BRADA, J. C.; DRABEK, Z.; MENDEZ, J. A.; PEREZ, M. F. National levels of corruption and foreign direct investment. Journal of Comparative Economics, 47(1), 31-49., 2019. Disponível em: https://doi.org/10.1016/j.jce.2018.10.005. Acesso em: 29 abr. 2021.

BRASIL. Constituição da República Federativa do Brasil. Brasília: Senado Federal, Centro Gráfico, 1988.

CARVALHO FILHO, J. D. S. Manual de direito administrativo. [s.l): [s.n], 2019.

CIEŚLIK, A.; GOCZEK, Ł. Control of corruption, international investment, and economic growth - Evidence from panel data. World Development, 103, 323-335, 2018. Disponível em: https://doi. org/10.1016/j.worlddev.2017.10.028. Acesso em: 29 abr. 2021. COORAY, A.; DZHUMASHEV, R. The effect of corruption on labour market outcomes. Economic Modelling, 74(January), 
207-218, 2018 Disponível em: https://doi.org/10.1016/j. econmod.2018.05.015. Acesso em: 29 abr. 2021.

CORRADO, G.; ROSSETTI, F. Public corruption: a study across regions in Italy.

Journal of Policy Modeling, 40(6), 1126-1139, 2018. Disponível em: https://doi.org/10.1016/j.jpolmod.2018.01.001. Acesso em: 29 abr. 2021.

EJIOGU, A.; EJIOGU, C.; AMBITUUNI, A. The dark side of transparency: Does the Nigeria extractive industries transparency initiative help or hinder accountability and corruption control? British Accounting Review, (August), 0-1, 2018. Disponível em: https://doi.org/10.1016/j.bar.2018.10.004. Acesso em: 29 abr. 2021.

FAORO, R. Os donos do Poder: formação do patronato político brasileiro. Rio de Janeiro. Globo Livros, 1913.

FATH, S.; KAY, A. C. "If hierarchical, then corrupt": exploring people's tendency to associate hierarchy with corruption in organizations. Organizational Behavior and

Human Decision Processes, 149(September), 145-164, 2018. Disponível em: https://doi.org/10.1016/j. obhdp.2018.10.004. Acesso em: 29 abr. 2021.

FILGUEIRAS, F. A tolerância à corrupção no Brasil: uma antinomia entre normas morais e prática social. Opinião Pública, 15(2), 386421.2009.

FU, Y. (2019). The value of corporate governance: evidence from the Chinese anticorruption campaign. North American Journal of Economics and Finance, 47(June 2018), 461-476. Disponível em: https://doi.org/10.1016/j.najef.2018.06.001. Acesso em: 29 abr. 2021.

FURTADO, Lucas Rocha. As raizes da corrupção no Brasil: estudo de casos e lições para o futuro. Belo Horizonte: Editora Fórum, 2015. GANS-MORSE, J.; BORGES, M.; MAKARIN, A.; MANNAHBLANKSON, T.; NICKOW, A.; e ZHANG, D. Reducing bureaucratic corruption: interdisciplinary perspectives on what works. World Development, 105, 171-188, 2018. Disponível em: 
https://doi.org/10.1016/j.worlddev.2017.12.015. Acesso em: 29 abr. 2021.

GROSSI, G.; PIANEZZI, D. The new public corruption: old questions for new challenges. Accounting Forum, 42(1), 86-101, 2018. Disponível em: https://doi.org/10.1016/j.accfor.2016.05.002. Acesso em: 29 abr. 2021.

HUANG, F.; CHEN, X.; WANG, L. Evolution of cooperation in a hierarchical society with corruption control. Journal of Theoretical Biology, 449, 60-72, 2018. Disponível em: https://doi. org/10.1016/j.jtbi.2018.04.018. Acesso em: 29 abr. 2021.

HUNTINGTON, S. P. A ordem politica nas sociedades em mudança. São Paulo: EDUSP, Rio de Janeiro: Forense-Universitária, 1975.

IBOPE. Índice de confiança social, 1988. Disponível em: http:// www.ibopeinteligencia.com/noticias-e-pesquisas/confianca-dobrasileiro-nasinstituicoes-e-a-mais-baixa-desde-2009/. Acesso em: 13 abr. 2019.

IPEA. Atlas do funcionalismo público federal, 2019. Disponível em: http://www.ipea.gov.br/atlasestado/filtros-series/2/ funcionalismo-federal. Acesso em: 13 abr. 2019.

KIM, D. S.; LI, Y.; TARZIA, D. Value of corruption in China: evidence from anti-

corruption investigation. Economics Letters, 164, 112-116, 2018. Disponível em: https://doi.org/10.1016/j. econlet.2018.01.021. Acesso em: 29 abr. 2021.

KULACHAI, W.; AMARAPHIBAL, A. Developing a causal model of turnover intention of police officers in the eastern region of Thailand. International Journal of Arts \& Sciences, 10(01), p. 473486. 2017.

MANION, M. La experiencia de Hong Kong contra la corrupción. Algunas lecciones importantes. Nueva Sociedad, 145, 126-137, 1996. MEIRELES, Olívia. Metrópoles é o $15^{\circ}$ site mais acessado do Brasil de acordo com a Amazon, 2018. Disponível em: https://www. metropoles.com/brasil/imprensa/metropoles-e-o-15-sitemaisacessado-do-brasil-de-acordo-com-a-amazon. Acesso em: 13 
abr. 2019.

NAM, T. Examining the anti-corruption effect of e-government and the moderating effect of national culture: A cross-country study. Government Information Quarterly, 35(2), 273-282, 2018. Disponível em: https://doi.org/10.1016/j.giq.2018.01.005. Acesso em: 29 abr. 2021.

NEKOVEE, M.; PINTO, J. Modeling the impact of organization structure and whistle-blowers on intra-organizational corruption contagion. Physica A: Statistical

Mechanics and Its Applications, 522, 339-349, 2019. Disponível em: https://doi.org/10.1016/j.physa. 2019.01.140. Acesso em: 29 abr. 2021.

OECD. Specialised Anti-Corruption Institutions: Review of Models, 2008.

OLIVIERI, C. Combate à corrup̧̧ão e controle interno. Ética pública e controle da corrupção, 2011.

PAIVA, F. B. Mitos e factos no combate à corrup̧̧ão, uma reflexão do estado da arte. Dissertação de mestrado. Universidade Técnica de Lisboa. Disponível em: http://hdl.handle.net/10400.5/1170. Acesso em: 29 abr. 2021.

POLÍCIA FEDERAL. Histórico. Disponível em: http://www. pf.gov.br/institucional/historico. Acesso em: 12 mar. 2019.

POPOVA, M.; POST, V. Prosecuting high-level corruption in Eastern Europe. Communist and Post-Communist Studies, 51(3), 231-244, 2018. Disponível em: https://doi.org/10.1016/j. postcomstud.2018.06.004. Acesso em: 29 abr. 2021.

PRASAD, M.; MARTINS DA SILVA, M. B.; NICKOW, A. Approaches to Corruption: a Synthesis of the Scholarship, 2018. Studies in Comparative International Development. Disponível em: https://doi.org/10.1007/s12116-018-9275-0. Acesso em: 29 abr. 2021.

REZZOAGLI, B. A. La Ubicación Institucional de las Agencias Anticorrupción: Un Debate Vigente. Políticas Públicas, 8(2), 2015. SOLÉ-OLLÉ, A.; SORRIBAS-NAVARRO, P. Trust no more? 
On the lasting effects of corruption scandals. European Journal of Political Economy, 55(December 2017), 185-203, 2018. Disponível em: https://doi.org/10.1016/j.ejpoleco.2017.12.003. Acesso em: 29 abr. 2021.

ZHANG, H.; AN, R.; ZHONG, Q. Anti-corruption, government subsidies, and investment efficiency. China Journal of Accounting Research, 12(1), 113-133, 2019. Disponível em: https://doi. org/10.1016/j.cjar.2018.12.001. Acesso em: 29 abr. 2021.

ZHANG, H.; SONG, Y.; TAN, S.; XIA, S.; ZHANG, H.; JIANG, C.; LV, Y. Anti-corruption efforts, public perception of corruption, and government credibility in the field of real estate: an empirical analysis based on twelve provinces in China. Cities, 90(December 2018), 64-73, 2019. Disponível em: https://doi.org/10.1016/j. cities.2019.01.042. Acesso em: 29 abr. 2021. 